\title{
Public knowledge, attitude and practice toward diabetes mellitus in Hail region, Saudi Arabia
}

This article was published in the following Dove Press journal:

International Journal of General Medicine

\author{
Mohamad Aljofan' \\ Ali Altebainawi ${ }^{2-4}$ \\ Mubarak Nsha Alrashidi ${ }^{2}$ \\ 'Department of Biomedical Sciences, \\ Nazarbayev University School of \\ Medicine, Astana 010000, Kazakhstan; \\ ${ }^{2}$ Pharmacy College, Hail University, Hail, \\ Kingdom of Saudi Arabia; ${ }^{3}$ Aja \\ Pharmaceutical Industries Co. Ltd, \\ Riyadh, Saudi Arabia; ${ }^{4}$ Medication Safety \\ Research Chair - KSU, Riyadh, Saudi \\ Arabia
}

Background: There is a rapid increase in the number of people with type II diabetes worldwide with many preventable cases. Diabetes control or prevention is partially influenced by the individual's knowledge, attitude and practice toward the disease.

Objective: The aim of this study was to determine the general public knowledge, attitude and practice toward diabetes in the region of Hail, which is located northern of the Saudi capital.

Methodology: This is a cross-sectional study conducted during the period of March 2018 until September 2018. We randomly selected participants over the age of 18 years at different locations.

Results: A total of 738 participants (428 females and 310 males) with and an age range of 18-61 years and mean age of $35 \pm 12$ were surveyed. The majority of the participants, regardless of education levels, residence and employment status showed high knowledge of diabetes $(82 \%)$ and knew that physical activity can positively affect/prevent diabetes. Participant's age was found to have a significant association with participant's knowledge of diabetes with the $\geq 35$ year old group knew the different types of diabetes $(p<0.001)$ and knew that high carbohydrate consumption can increase the risk of diabetes $(p<0.001)$, but only the younger group $<18$ year old's identified diabetes as a genetic disorder $(p<0.001)$.

Conclusion: The high knowledge of the disease and its risk factors were not truly mirrored in the participant's attitude and practice toward the disease. Therefore, it is quite essential for the local health authorities to implement awareness programs to improve public attitude and practice toward diabetes.

Keywords: knowledge, attitude, practice, diabetes mellitus, general population

\section{Background}

Diabetes mellitus (DM) is a chronic metabolic disorder that can affect the patients' quality of life and increases their risks of developing other diseases. ${ }^{1,2}$ Patients with diabetes are at higher risks of developing other health-related complications, including four times more likely to develop cardiovascular complications, ${ }^{3,4}$ fertility complications, ${ }^{5}$ and twice as likely to develop renal diseases as the general population. ${ }^{6}$

In 2013, the global prevalence of people with diabetes was estimated at 382 million and expected to rise to 592 million by $2035 .^{7}$ However, reports for 2018 estimated that there are more than 500 million prevalent cases of type 2 diabetes worldwide, and the prevalence is comparable between high- and low-income countries. ${ }^{8}$

Currently, there are 23 million adults who have been diagnosed with diabetes in the US and it is estimated that the prevalence of diabetes will rise to $5.5 \%$ in 2025 as compared to $4 \%$ in the year $1995 .{ }^{9}$ However, the prevalence of diabetes is
Correspondence: Mohamad Aljofan Department of Biomedical Sciences, Nazarbayev University School of Medicine, Astana 010000, Kazakhstan Tel +7 7172694986

Email Mohamad.aljofan@nu.edu.kz 
estimated to be significantly higher in other parts of the world including the Middle East, which would have the highest prevalence over the coming years due to rapid economic growth, development and changes in diet patterns. ${ }^{10}$ One of these countries is Saudi Arabia, which is witnessing a tremendous economical and developmental growth $^{11}$ that is predicted to affect the lifestyle pattern and possibly increasing the prevalence of diabetes in the country. In 2010, the Saudi Arabian Ministry of Health reported that the number of people with diabetes in the country is to be approximately 2.5 million and continuing to rise at a highly increasing rate. ${ }^{12}$

Evidence suggests that the prevalence is affected by various factors such as sociodemographic, health knowledge and early diagnosis. ${ }^{13}$ Thus, it is quite essential to determine the level of general knowledge and to perhaps increase knowledge as part of controlling or reducing the prevalence. Therefore, the objective of the current study is to determine the knowledge, attitude and practice of the general population in Hail region, which is located in the northern part of Saudi Arabia toward diabetes, its treatment and management.

\section{Methodology}

\section{Ethics approval}

A submission, including full project proposal and consent forms, was made to the Scientific Research Ethical Committee (SREC) at the University of Hail in the Kingdom of Saudi Arabia. The Committee unconditionally approved the project and agreed to verbal consent to be used.

\section{Calculating sample size}

The following formula was used to determine the sample size at $99 \% \mathrm{CI}$ :

$$
n=\frac{Z^{2}(P)(1-P)}{d^{2}}
$$

where

$n=$ sample size,

$Z=Z$ statistic for a level of confidence,

$P=$ standard deviation

$d=$ margin of errors

For the level of confidence of $99 \%$, which is conventional, $Z$ value is 2.576 .

$$
N=\frac{\left[(2.576)^{2} \times(0.5 \times(1-0.5))\right]}{(0.05)^{2}}
$$

$=663.57$, therefore 664 participants are needed to achieve the required $\mathrm{CI}$.

\section{Study design}

This is a cross-sectional questionnaire-based study. Participants were randomly selected at shopping centers, recreational parks and outpatient clinics at local hospitals and were consented to participate after they were given full details of the study and its intended aims. The questionnaire was designed in English and then translated to the local spoken language Arabic by proficient speakers of both languages and was revised to be suitable to the general population.

\section{Questionnaire}

The questionnaire used in the current study was developed to evaluate the participant's KAP regarding diabetes, its risk factors and management. The questionnaire contained 6 questions divided into four sections. The first section collected demographic information of the participants. The second section contained questions about knowledge of DM. The third section collected information about the practices of participants toward disease and disease management including medication and the necessary lifestyle changes. The last section collected information about their general attitude toward diabetes. In order to validate the questionnaire, a pilot run was performed using a group of 25 randomly selected individuals. A total of 15 participants were recruited from Garden Shopping Center, and the remaining 10 participants were recruited from Hail General Hospital. The participants were informed of the study and consented to voluntarily participate. The final corrected version of the questionnaire was used for this study.

\section{Study population (inclusion/exclusion)}

Inclusion: We only included male and female $\geq 18$ years of age. Exclusion: People who were less than 18 years old, mentally handicapped, those who did not consent to participate, participants with medical background (all healthrelated education) and those who had attended a diabetes education programs in the last 6 months were excluded from the study.

\section{Data storage}

All data collection forms were kept in a secure setting, only available to the principal investigator, and will be destroyed by the principal investigator after completion 
of the study, in accordance with the requirement of the SREC at the University of Hail.

\section{Statistical analysis}

Data were recorded on a data collection form and entered on a Microsoft Office Excel $^{\circledR}$ (2010) spreadsheet. Statistical data analyses and tables were generated using Microsoft Office Excel $^{\circledR}$ (2010). A Chi-squared test was used to test for significance, and a priori level of $p<0.01$ was considered statistically significant.

\section{Results}

\section{Demographic data}

A total of 754 questionnaires were collected, of which 16 questionnaires were excluded as some participants listed their age as less than 18 years and others have selected more than one answer for some of the questions, giving a response rate of $97.8 \%$. Therefore, 738 questionnaires were included in the study.

Approximately, $60 \%$ of the respondents were from Hail urban region (446), of whom 428 were females $(58 \%)$ compared to 310 males (42\%), with the majority of the respondents in the 18-35 years' age group (76.6\%). Interestingly, the respondents recorded close to $70 \%$ for both their educational background, completed high school and above, as well as being employed. These results are a true reflection of the age group being of working age as well as the educational level of the people in that region, as older respondents would have lower educational levels. The characteristics of the studied population are shown in Table 1.

\section{Knowledge assessment}

Approximately, $84 \%$ of the respondents knew what diabetes is, but only $57 \%$ knew the different types. Interestingly, respondents in the $\geq 35$ years' old age group scored significantly higher $(p<0.001)$ in knowledge of the different types of diabetes as well as linking carbohydrate consumption with diabetes control $(p<0.001)$ compared to the younger counterparts. While all respondents knew that exercise will improve/prevent diabetes, respondents in urban areas and those with college degrees recorded significantly higher when asked whether diabetes was a genetically linked disorder $(p<0.001)$ (Table 2). A total of $47 \%$ of the respondents

Table I Characteristics of the research population

\begin{tabular}{|c|c|c|}
\hline Variables & $\mathbf{N}$ & Percentage \\
\hline \multicolumn{3}{|l|}{ Gender } \\
\hline Male & 310 & 42 \\
\hline Female & 428 & 58 \\
\hline \multicolumn{3}{|c|}{ Age, years (range I8-6I) } \\
\hline Mean $\pm S D^{*}$ & $35 \pm 12$ & \\
\hline $18-34$ & 566 & 76.6 \\
\hline $35-60$ & 171 & 23.2 \\
\hline$>60$ & I & 0.2 \\
\hline \multicolumn{3}{|c|}{ Level of education } \\
\hline None & 106 & 14.4 \\
\hline Primary & 124 & 16.8 \\
\hline High school & 284 & 38.5 \\
\hline College & 224 & 30.3 \\
\hline \multicolumn{3}{|c|}{ Employment status } \\
\hline Working & 502 & 68 \\
\hline Not working & 236 & 32 \\
\hline \multicolumn{3}{|l|}{ Residence } \\
\hline Urban & 446 & 60.5 \\
\hline Rural & 292 & 39.5 \\
\hline
\end{tabular}

Notes: The table shows the characteristics of the respondents. After consenting to participate in the study, participants were asked to provide the following information: gender, age, level of education, employment and residence. Level of education: none, represents those who did not attend school or did not complete 6 years of study; primary, those who completed more than 6 but less than 12 years of studies; high school, represents participants who have at least completed I 2 years of studies; college, those who completed a diploma and above. *SD of the mean. 


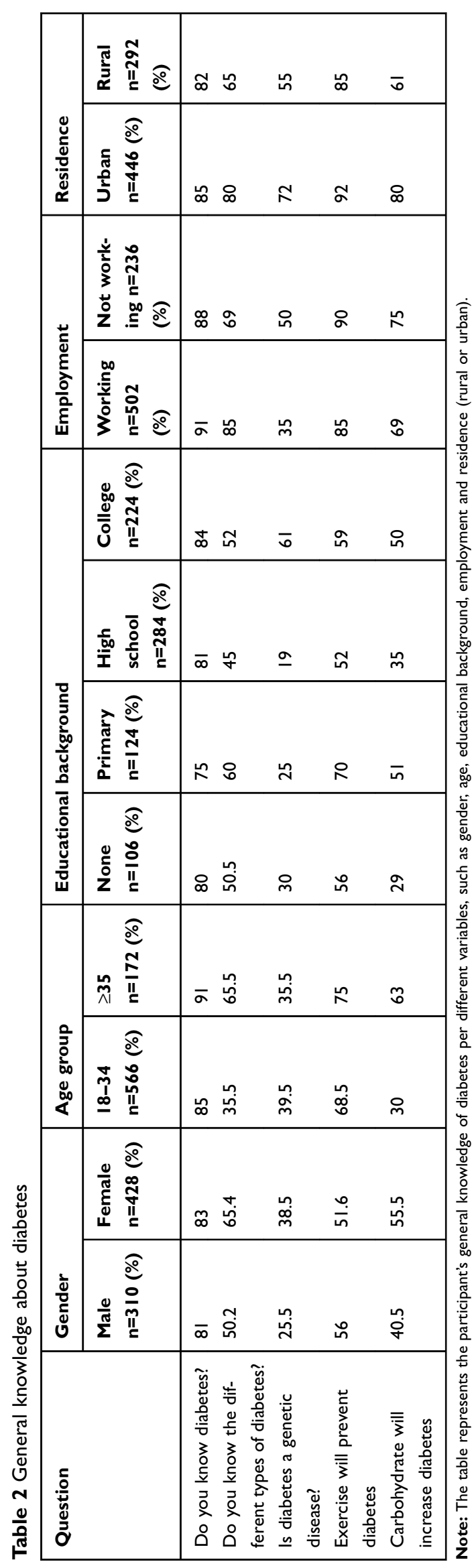


knew that uncontrolled diabetes will lead to affect other organs; however, the remainder either do not believe $(20 \%)$ or do not know that uncontrolled diabetes can affect other organs $(33 \%)$. Of those who knew the effect of diabetes on health, $24.5 \%$ thought that diabetes will lead to eye disease, $28 \%$ believed it affects the kidneys, $26 \%$ listed foot ulcers and $20 \%$ only believed that diabetes can cause heart problems (Figure 1).

\section{Attitude toward DM}

After adjusting the respondent's characteristic variables, residence, level of education and employment status were not associated with attitudes toward DM; however, respondents in the 18-34 years' old age group showed a significantly higher positive attitude toward therapeutic management of DM (OR 95\% CI, 1.37 (0.85-2.21), $p=0.01$ ), than the older group. Furthermore, 302 respondents $(40 \%)$ believed that the use of alternative medicines including herbs is more beneficial than the standard medication. A total of $150(20 \%)$ believed that the long-term use of diabetes treatment is harmful. Interestingly, $25 \%$ $(n=185)$ of the respondents believed that diabetes is a temporary disease and $30 \%(n=222)$ believed that medications can be immediately stopped once diabetes is controlled (Figure 2).

\section{Practice assessment}

Oof the 738 total respondents, 148 (20\%) were diabetics for more than 5 years, with 55 reported to have checked their blood glucose levels (BGL) twice a year $(37.1 \%), 91$ reported to have checked once yearly
$(61.5 \%)$, and only two respondents claimed that they have never checked their BGL(1.4\%). Approximately, $60 \%$ of the diabetic respondents (89) claimed to have attended at least one diabetes educational program since their first diagnosis, and $80 \%$ of those have adapted lifestyle changes to improve their BGLs. Interestingly, we found that men were twice as likely to adapt lifestyle changes as women, 78\% compared with $40 \%$, respectively. Educational levels, residence, and employment status were not associated with the practice (Table 3 ).

\section{Discussion}

There is a global increase in the prevalence of type II DMthat is predicted to rapidly rise over the next decade, particularly in developing countries. In 2014, the WHO reported that $8.5 \%$ of adults aged 18 years and older had diabetes and that this number is set to significantly increase. $^{14}$

It is widely known that patient's knowledge, attitude and practice toward a disease will significantly affect the treatment outcome. ${ }^{15}$ In fact, studies have shown a strong correlation between T2DM knowledge and hemoglobin A1C level. ${ }^{16}$ In the current study, we aimed to investigate the knowledge, attitude and practice of the general population in the region of Hail toward DM. We surveyed 738 participants, of which $58 \%$ were females, more than $76 \%$ of the participants were in the 18-35-year-old group and the majority were either studying or working full time, which is an expected percentage of a cohort in this age group.

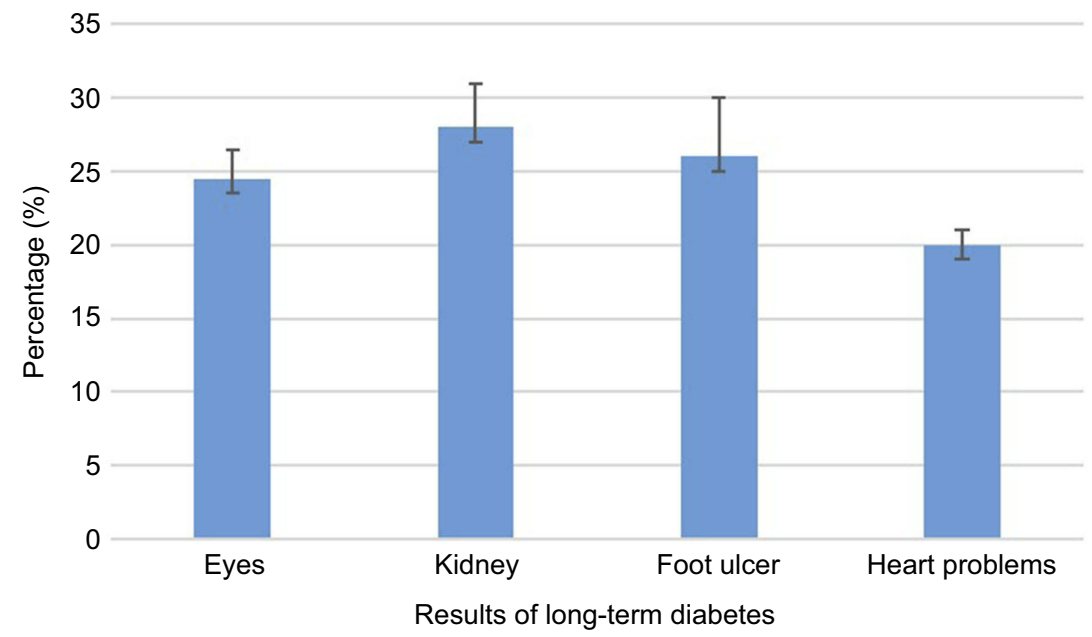

Figure I Effect of diabetes on other organs. Participants who believed that diabetes can affect other organs were asked to select or write any organ/ disease that may result from diabetes. 


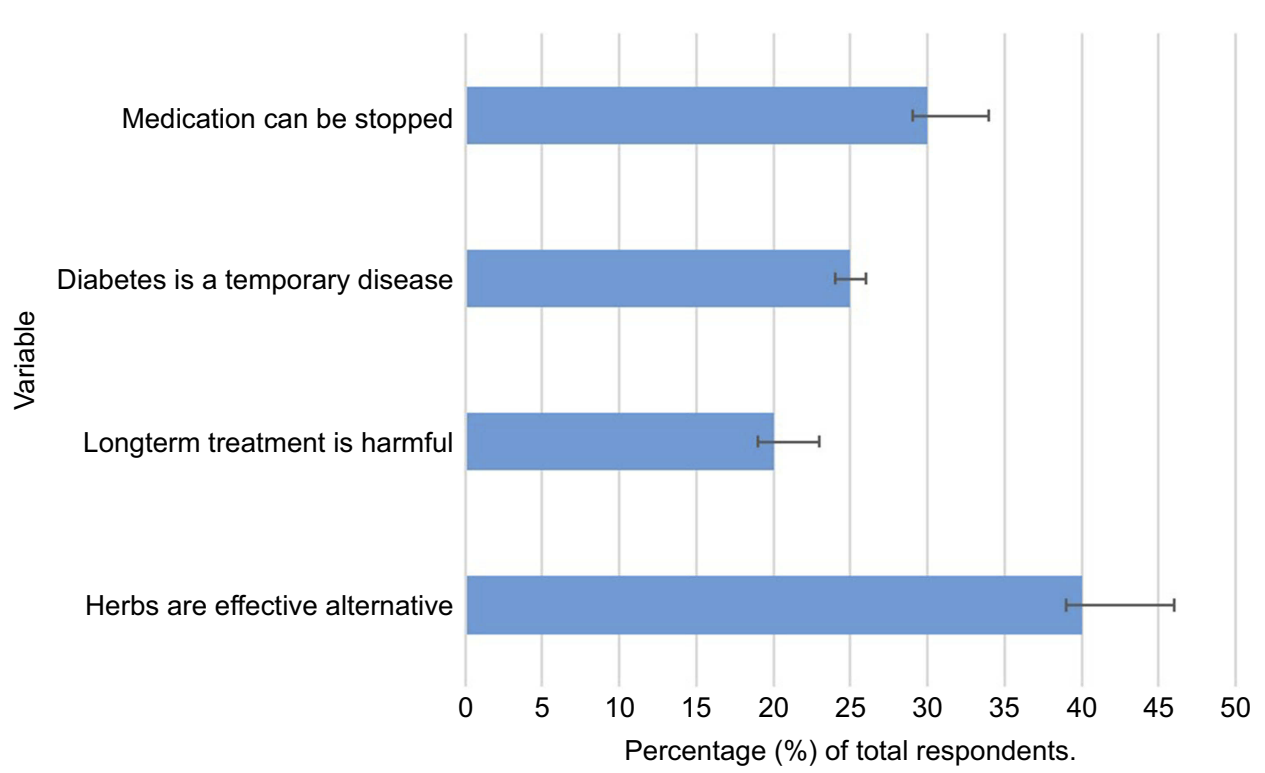

Figure 2 Attitude toward diabetes. The graph represents the participant's attitude toward diabetes and its treatment. They were asked whether diabetes is a lifelong disease or a temporary one, can they stop taking their medication after they control diabetes, and whether long-term usage of diabetic medicine is harmful. Also, they were asked whether they believe that traditional herbs can provide reliable alternatives to standard medications.

Generally, participants showed high disease knowledge with $84 \%$ of the respondents showed good knowledge of diabetes, and they understand the benefit of exercise on controlling or preventing diabetes, but only the older age group ( $\geq 35$ years old) were better informed of the different types of diabetes and the food that can adversely affect BGLs. Expectedly, knowledge analysis indicated that education level and residence (urban vs rural) can impact one's knowledge about the diseases as college graduates and urban dwellers were the only groups who knew that diabetes was a genetically linked disease (Table 2). These differences may likely be due to two major reasons; first is the availability of education centers around the city and second is the large number of awareness campaigns that are carried out in schools and colleges.

Interestingly, the 18-35 years' old group showed a better attitude toward diabetes and its therapeutic management than the older cohort (Figure 2). This could be due to the widespread usage of herbal and natural remedies among people in the area, which is predominantly practiced among the older generation, thus explaining the positive attitude shown with the younger group. ${ }^{17}$ Another possible reason for an improved attitude within the young cohort is that the younger generation are better educated than the older cohort, and thus are more likely to have good awareness that led to better attitude and practice.

Table 3 Assessment of practice

\begin{tabular}{|l|l|l|l|l|}
\hline \multicolumn{2}{|l|}{} & Males (\%) & Females (\%) & P \\
\hline Checked BGL & Never & 1.4 & $0.0 \%$ \\
& Once & 36.9 & 37.3 \\
& Twice or more & 65 & 58 & 0.12 \\
\hline Attended diabetes education centers & At least one & 49 & 70 & 30 \\
& Never & 51 & 40 & 0.02 \\
\hline Adapted lifestyle changes & Yes & 78 & 60 & $<0.00 I^{*}$ \\
& No & 22 & & \\
\hline
\end{tabular}

Notes: Participants with diabetes were asked several practice questions, including the frequency of measuring their blood glucose level since diagnosis, attending diabetes awareness centers, which are available throughout the region, or whether they believed in changing lifestyle effect on diabetes as well as their willingness to do so. *Significant. 
Contrary to previous reports in Saudi Arabia that claimed females were more willing than males to adapt to lifestyle changes, ${ }^{18}$ the current study found that males were more eager to adapt to lifestyle changes than females. While there might be several reasons that could explain the difference, we can speculate that the difference is due to the willingness of male participants in quitting smoking. Notably, smoking was listed as part of lifestyle changes; however, the region has a very low rate of female smokers, which may explain the high rate of lifestyle changes in the male cohort compared to the females.

Analysis of several studies that investigated the disease prevalence in Saudi Arabia showed a steady increase in the disease prevalence over the last decades including a study by Baghli et al that estimated the prevalence rate to be at $18.2 \%$ in $2004,{ }^{19}$ and a study by Daghri et al, which was published less than 10 years after, estimated the prevalence to be at $31.6 \%{ }^{20}$ However, most recent official reports suggested diabetes prevalence to be at $18.5 \%,{ }^{10,12}$ which is quite close to our current findings in the Hail region.

\section{Limitations}

The respondents were recruited at different sites including shopping centers, recreation sites and outpatient clinics, which could explain the high proportion of young participants. Also, the study is done in a relatively small region in the northern part of Saudi Arabia, which may not necessarily be a true reflection of the general public. The sample size is not representative of the studied region, which is estimated to have close to 2 million residence; however, participants were from wide geographic area and, thus we can consider it as a representative sample. Finally, the studied sample reported $20 \%$ prevalence of diabetes, which is comparable to that of the official reported figures of $18.5 \% .^{10}$

\section{Conclusion}

The results show that the majority of participants have a good general knowledge of diabetes, but poor attitude and practice toward its risk factors and management. Given the continual increase in the prevalence of the disease, urgent measures need to be implemented to improve disease control and management including awareness campaigns that aim to improve disease knowledge and management. Therefore, the current study can be used as a point of direction for future awareness campaigns in the Hail region with a particular focus on attitude and practice.

\section{Acknowledgments}

This work would not have been possible without the help of each participant. The authors appreciate the great help of the students who distributed and collected the surveys. Also, we would like to thank Prof Robert Smith for reviewing the manuscript.

\section{Disclosure}

The authors declare no conflicts of interest in this work.

\section{References}

1. Aljofan M, Ding H. High glucose increases expression of cyclooxygenase-2, increases oxidative stress and decreases the generation of nitric oxide in mouse microvessel endothelial cells. $J$ Cell Physiol. 2010;222(3):669-675. Epub 2009/ 12/02. PubMed PMID: 19950211. doi: $10.1002 /$ jcp. 21986

2. Ding H, Aljofan M, Triggle CR. Oxidative stress and increased eNOS and NADPH oxidase expression in mouse microvessel endothelial cells. J Cell Physiol. 2007;212(3):682-689. Epub 2007/04/20. PubMed PMID: 17443690. doi: 10.1002/jcp.21063

3. Roper NA, Bilous RW, Kelly WF, Unwin NC, Connolly VM, South Tees Diabetes Mortality S. Cause-specific mortality in a population with diabetes: south tees diabetes mortality study. Diabetes Care. 2002;25(1):43-48. Epub 2002/ 01/05.PubMed PMID: 11772899. doi: $10.2337 /$ diacare.25.1.43

4. Aljofan MGA. Metformin: a stroke of luck. Electron J Gen Med. 2019;16(3):em143.

5. Paule S, Aljofan M, Simon C, Rombauts LJ, Nie G. Cleavage of endometrial alpha-integrins into their functional forms is mediated by proprotein convertase 5/6. Hum Reprod. 2012;27(9):2766-2774. Epub 2012/06/29. PubMed PMID: 22740495. doi: 10.1093/humrep/des203

6. Narres M, Claessen H, Droste S, et al. The incidence of end-stage renal disease in the diabetic (Compared to the non-diabetic) population: a systematic review. PLoS One. 2016;11(1):e0147329. Epub 2016/ 01/27. PubMed PMID: 26812415; PubMed Central PMCID: PMCPMC4727808. doi: 10.1371/journal.pone.0147329

7. Forouhi NG, Wareham NJ. Epidemiology of diabetes. Medicine (Abingdon). 2014;42(12):698-702. Epub 2015/ 01/09. PubMed PMID: 25568613; PubMed Central PMCID: PMCPMC4282306. doi: 10.1016/j.mpmed.2014.09.007

8. AMY BRADSHAW KAISER NZaWVDP. Global prevalence of type 2 diabetes over the next ten years (2018-2028). Diabetes. 2019;67 (Supplement 1):202. doi:10.2337/db18-202-LB

9. CDC. National Diabetes Statistics Report In: US Department of Health and Human Services C, Editor. CDC; 2018.

10. Aguiree Florencia BA, Ho CN, Gisela D, et al. IDF Diabetes Atlas. 7th ed. Basel, Switzerland: International Diabetes Federation; 2015.

11. Aljofan M. The era of scientific blossom. J Antivir Antiretrovir. 2012. doi: $10.4172 /$ jaa. $1000 \mathrm{e} 102$

12. Health SMo. Health Statistics Report. ed2018. Accessed 2019.

13. Demaio AR, Otgontuya D, de Courten M, et al. Exploring knowledge, attitudes and practices related to diabetes in Mongolia: a national population-based survey. BMC Public Health. 2013;13:236. Epub 2013/ 03/20. PubMed PMID: 23506350; PubMed Central PMCID: PMCPMC3606830. doi: 10.1186/1471-2458-13-236

14. Organization WH. USA. Diabetes; 2019.

15. Gillani AH, Islam FMA, Hayat K, et al. Knowledge, attitudes and practices regarding diabetes in the general population: a cross-sectional study from Pakistan. Int J Env Res Pub He. 2018:15(9):ARTN 1906. PubMed PMID: WOS:000445765600115. doi:10.3390/ijerph 15091906 
16. OY F, Erol A, Muhittin AS, Omer U, Ejder K, Ismail K. Association between glycemic control and the level of knowledge and disease awareness in type 2 diabetic patients. Pol Arch Med Wewn. 2010;120:399-406.

17. Aljofan M, Netter HJ, Aljarbou AN, et al. Anti-hepatitis B activity of isoquinoline alkaloids of plant origin. Arch Virol. 2014;159(5):11191128. Epub 2013/ 12/07. PubMed PMID: 24311152. doi: 10.1007/ s00705-013-1937-7

18. Albargawi M, Snethen J, Gannass AA, Kelber S. Perception of persons with type 2 diabetes mellitus in Saudi Arabia. Int $J$ Nurs Sci. 2016;1(3):39-44.
19. Al-Baghli NA, Al-Ghamdi AJ, Al-Turki KA, Al Elq AH, El-Zubaier AG, Bahnassy A. Prevalence of diabetes mellitus and impaired fasting glucose levels in the Eastern Province of Saudi Arabia: results of a screening campaign. Singapore Med J. 2010;51(12):923-930. Epub 2011/ 01/12.PubMed PMID: 21221496.

20. Al-Daghri NM, Al-Attas OS, Alokail MS, Alkharfy KM, Yousef M, Sabico SL. Diabetes mellitus type 2 and other chronic non-communicable diseases in the central region, Saudi Arabia (Riyadh cohort 2): a decade of an epidemic. BMC Med. 2011;1(9):1.
International Journal of General Medicine

\section{Publish your work in this journal}

The International Journal of General Medicine is an international, peer-reviewed open-access journal that focuses on general and internal medicine, pathogenesis, epidemiology, diagnosis, monitoring and treatment protocols. The journal is characterized by the rapid reporting of reviews, original research and clinical studies

\section{Dovepress}

across all disease areas. The manuscript management system is completely online and includes a very quick and fair peer-review system, which is all easy to use. Visit http://www.dovepress.com/ testimonials.php to read real quotes from published authors. 